\title{
The Impact of a Self-Control Training Program on Enhancement of Social Skills in Students with ADHD
}

\author{
Ahmad Beh-Pajooh ${ }^{1 *}$, Sayyed Mohsen Fatemi ${ }^{2}$, Bagher Ghobari Bonab ${ }^{1}$, \\ Hamid Alizadeh ${ }^{3}$, Ghorban Hemmati ${ }^{4}$ \\ ${ }^{1}$ Faculty of Psychology \& Education, University of Tehran, Tehran, Iran \\ ${ }^{2}$ Department of Psychology, Harvard University, Cambridge, USA \\ ${ }^{3}$ Faculty of Psychology \& Education, Allameh Tabataba’i University, Tehran, Iran \\ ${ }^{4}$ Faculty of Psychology \& Education, Shiraz University, Shiraz, Iran \\ Email: behpajooh@ut.ac.ir,smfatemi@wjh.harvard.edu,bghobari@ut.ac.ir, \\ hamidalizadeh1@yahoo.com, hemati@ut.ac.ir
}

Received February $15^{\text {th }}$, 2012; revised April $7^{\text {th }}$, 2012; accepted June $10^{\text {th }}, 2012$

\begin{abstract}
Objective: The study examined the effect of a self-control training program on enhancing social skills in students with ADHD. Method: The study selected a pre-test-posttest control group design for a sample of twenty male students in an elementary school in Tehran, Iran. The sample was divided into experimental and control groups with the implementation of the treatment for the random assignment of the experimental group for the period of one month. A repeated measure method was performed to analyze the data. Results: The results indicated that the self-control training procedure was significantly effective in improving the social skills of students with ADHD. The follow-up data indicated the effectiveness of the treatment after the lapse of one month. Conclusion: The results suggested that teaching self-control techniques to students with ADHD would enhance their social skills.
\end{abstract}

Keywords: Self-Control Procedure; Social Skills; Attention Deficit Hyperactivity Disorder

\section{Introduction}

Attention Deficit Hyperactivity Disorder (ADHD) appears to be one of the most common and prevalent psychological and neurodevelopmental disorders among children characterized by more inattention, hyperactivity and impulsivity difficulties (DSM-IV-TR, American Psychiatric Association [APA], 2000). ADHD has been reported to be the main reason behind the referrals of $30 \%$ to $40 \%$ of school-age children to mental health counseling centers (Cantwell, 1996; Goldstein, 1995). It is estimated that $3 \%-7 \%$ of school-age children suffer from ADHD in the United States (APA, 2000; Conners \& Jett, 1999). The prevalence rate of ADHD symptoms in other countries also indicates nearly the same. For example, Khoushabi and Pouretemad (2002) have reported that 3\% - 5\% of Iranian high school students suffer from ADHD. More specifically, Ghanizadeh (2008) has declared that $10.1 \%$ of primary students have ADHD symptoms. The existing evidence also reveals gender differences of children with ADHD in Iran, whereas boys are reported to be 3 to 10 times more susceptible to this disorder than girls (Khoushabi \& Pouretemad, 2002).

Core difficulties in children with ADHD include problems in sustaining attention, poor impulsive and hyperactivity control. Since children with ADHD are more likely to display problems such as, emotional and behavioral disorders and to be impaired in social behaviors, a timely intervention program may be necessary to treat for them. The accurate diagnosis of the disorder and effective administration of prevention programs would play a significant role on preventing behavioral disorders and learning problems in such children. As Braswell (1998) and Braswell

"Corresponding author. and Bloomquist (1991) have reviewed the main aim of most intervention programs are teaching self-control and self regulation techniques to children with ADHD. Teaching self-control and self-regulation techniques may serve as an effective strategy to reduce the problems of these children (Austin, 2003; Murray, 2002; Pierangelo \& Giuliani, 2008; Whittenberg, 1995).

Self-control is defined as the response of choosing a delayed larger reinforcer over an immediate smaller reinforcer (Dixon et al., 1998; Gilmore, Cuskelly, \& Hayes, 2003). The term selfcontrol suggests the ability to manage and control impulsivity and ephemeral desires (Barkley, 1997). According to Russell Barkley (1990, 1997), understanding ADHD is inextricably tied to understanding of the nature of self-control.

Historically, cognitive-behavioral intervention programs have been developed and widely used for treatment of children with ADHD over 40 years. For example, Meichenbaum and Goodman (1971) examined the effect of self-directed speech in improving sustained attention and behavioral inhibitions in a group of impulsive children. Many children with ADHD have poor social skills as well as weak interpersonal relationships. According to Landau, Milich and Diener (1998), approximately fifty percent of children with ADHD experience peer rejection and for many of them, relationship with adults are problematic.

Gresham and Elliot (1984) have defined social skills as socially acceptable behaviors that enable a person to interact effectively with others to avoid socially rejection. Similarly, in their study of the personality of children with ADHD, Lufi and Parish-Plass (1995) found that these children were more dependent on an external source of control, had less emotional stability and suffered from more social anxiety. Children with $\mathrm{ADHD}$, therefore, may need assistance to notice the effects of 
their social behaviors on other people.

Children with ADHD often encounter problems in social interactions with their teachers and peers and may seem to be excluded on behalf of other children. Children with ADHD may not often know the reason of getting rejected by other children and may not see the connection between their behaviors and other children's lack of receptiveness. The typical behaviors of children with ADHD seem to be associated with inattention to other's feelings, irresponsibility, impulsivity, impatience and lack of cooperation in participatory tasks. Patience, therefore, is a skill that such children need to learn (Friedman \& Doyal, 1992).

Children with ADHD, thus, may need to realize the possible adverse consequences of their behaviors. This may also require learning appropriate and effective ways to meet the right needs. The wrong evaluation and lack of control may possibly generate faulty actions for children with ADHD. Self-control techniques that would contribute to the implementation of self-monitoring, self-evaluation and self-reinforcement may help these children make right choices and become aware of the consequences of their behaviors (Matson \& Ollendick, 1988).

Whittenberg (1995) studied the effects of training social skills and self-control techniques on a group of socially handicapped children. Fourteen boys and twenty-two girls at the fourth grade of ordinary schools participated in this pretest and post-test experimental research which lasted for 12 weeks. The experimental group with self-control training included eight participants and the one receiving social skills training had nine subjects. The control group with no intervention program consisted of 19 participants. The participants in the experimental groups received one hour treatment per week for a period of ten weeks. The findings indicated that both training methods had reduced social anxiety in participants. However, the self-control training program indicated a higher impact in comparison with the social skills training program.

Austin (2003) studied the effect of self-management techniques on the treatment of ADHD in school children. His study was an experimental pre-test post-test design including four primary school children. The intervention program consisted of a series of behavioral goals for children self-management and availability of a set of self-reinforcement alternatives. The findings indicated that in-class inappropriate behaviors especially academically irrelevant behaviors and hyperactivity significantly decreased in all participants due to the effect of the self-management techniques training. A follow-up study confirmed the maintenance of the results after one month.

Murray (2002) used cognitive-behavioral methods for teaching self-control techniques to pre-school children with impulsive behaviors. The study included 31 four-year-old children who were randomly assigned to experimental and control groups. The experimental group received self-control training techniques for five weeks using cognitive-behavioral techniques. The findings indicated that self-control ability had increased in children which lead to the reduction of the rates of impulsive behaviors.

In a similar study, Heinrich and colleagues (2004) examined the effect of training self-control techniques on elementary students with ADHD. The participants included thirteen 7 to 13 year-old children who received self-control training and relaxation exercises for 25 sessions in three weeks. The findings indicated behavioral improvement in ADHD children. Furthermore, the severity of ADHD had also decreased among the participants.

However, some findings have reported that self-control training has not been effective with high incidence populations, including children with ADHD (Abikoff, 1991). Yet, few studies have examined the effectiveness of such training over time and especially little research has been conducted in Iran. Therefore, it seems there is a need for more investigation and it was hoped that such knowledge would help teachers and school psychologists to maximize the effectiveness of self-control programs. In the present study it was hypothesized that students who had participated in self-control training programs, their prosocial behaviors would enhance more than those who had no experience of such training.

\section{Method}

\section{Participants}

The researchers used a pretest-posttest experimental research design with a control group. The population included all elementary school boys in Tehran who enrolled and attended in mainstream schools at the time of study. The independent variable was defined as the self-control training program with the dependent variable as the social skills.

The convenient sample included twenty male elementary school children with an average IQ scores (95 - 108) and the age range of $7-11$ years $(M=8.5$; $S D=1.8)$. They had been diagnosed by a psychiatrist as having the symptoms of ADHD based on the criteria of the DSM-IV (APA, 2000). The participants were not under any medication or therapy and were randomly assigned to the experimental and control groups. The experimental group received the self-control training intervention program while the control group received no treatment. All the participants' parents signed the consent forms to agree with participation of their children in this study.

\section{Instruments}

The study administered three instruments:

1) The 18-Item ADHD Checklist: The teachers were asked to rate each student on the 18-item ADHD checklist. The 18-item ADHD checklist was developed by Ghanizadeh (2010) on the basis of diagnostic criteria of the DSM $4^{\text {th }}$ (APA, 2000) to detect ADHD symptoms among potential students. The checklist has sufficient validity and reliability and uses a 4-point Likert-type (Likert, 1932) rating scale including often or always (3), sometimes (2), seldom (1), and never or not observed (0).

2) Raven's Progressive Matrices: Raven's Progressive Matrices measure was used to control the intelligence quotient of the students. The researchers used the 36-item color form of this measure for 6 - 9-year-old children and the 60-item form for children of 9 - 11. The reliability coefficient of this test for various age groups ranges between .70 and .90 . In addition, this measure has a correlation coefficient of $.40-.75$ with other intelligence tests, including Stanford Binnet and Wechsler Intelligence Scale for Children (Anastasi \& Urbina, 2009).

3) The Social Skills Rating System: The Social Skills Rating System (SSRS) was developed by Gresham and Elliott in 1990. The SSRS is a norm-referenced rating scale and provides a broad assessment of students' social behavior that can affect teacher-student relations. The SSRS includes three behavior rating forms for parents, teachers and students. The elementary 
school teacher form (grades K-6) was used in this study. This measure is based on a 30-item questionnaire rated on a three-point Likert type scale (Likert, 1932). Numerical scores 0, 1 , and 2 were assigned for the answers Never, Sometimes, and Very Often, respectively. Therefore, a score of 60 would be used potentially for the maximum score and zero for the minimum.

Internal consistency coefficient range from .83 to .94 was reported for the SSRS using test re-test method and Cronbach's alpha (Gresham \& Elliott, 1990). Furthermore, in a study in Iran, Cronbach's alpha and split-half methods estimated a reliability of .90 and .88 respectively by Shahim (1999). In addition, in the present study the researchers measured the reliability of the SSRS on a 100 sample of elementary students in Tehran obtaining a Cronbach's alpha of .87. Thus, the scale indicates a high degree of internal reliability. The content validity of the SSRS also was verified by five professors of psychology.

The SSRS questionnaire booklet was filled out by the teacher of each student. The questionnaire was administered three times. The first time, it was administered to both experimental and control groups as a pretest before the introduction of the intervention program. For the second time, it was re-administered at the end of the intervention program as the post-test to both groups. The third time of administration of the test was performed (on both groups) as a follow-up measurement one month after the second administration in order to measure the maintenance of the behavior changes.

\section{Intervention Program}

The self-control training program was consisted of teaching and reinforcing appropriate social behaviors of students and administered in four phases.

First Phase: At the beginning, the participants of the experimental group received instructions and were given a notebook with 15 pages in every page contained fifteen appropriate social skills, such as, "I should stay in my seat", "I should follow my teacher's instructions", and "I should drop the garbage in the dustbin". Then, during two successive sessions these social skills were introduced to the students and contingencies of performing these behaviors were described. The students were taught the appropriate social skills and their contingencies. The students also became acquainted of the token economy system and backup reinforcers.

Second Phase: In the second phase, a 45-minute orientation meeting was held with the teachers by the researcher regarding how to use token economy. Tokens were given to the teachers in order to use them in reinforcing students' appropriate behaviors. The teachers were given points to students' prosocial behaviors every day and adding them up to their cards each day in order to accumulate their points. For example, if a student was attentive, the teacher gives one point. However, if during the administration of the intervention program the student listened to the teacher more than one hour, he would be awarded one point for the listening skill. The teachers were trained to measure each student's social behavior in a similar manner (before and after the intervention program). Furthermore, teachers were asked to collect the notebooks at the end of each school day. The teachers would then give points the social skills according to the student's social performance on that day. At the end of each week, students were reminded of the accumulated reinforcers they had gotten. The students were instructed that in case of spending their tokens they can buy different desired objects. However, they were prompted to save their tokens and accumulate their marks to get a better and more precious object. This token economy program was lasted for a month. In this period of intervention students accumulated their reinforcers in order to buy a precious object they deserved. The students were also given reinforcement cards on the basis of their cumulative points. On the first day, the teacher added up scores and gave a reinforcement card immediately to the students. The points for the second and third days were aggregated and a reinforcement card was given accordingly. In a similar vein, points for the fourth, fifth and sixth days were aggregated and a cumulative reinforcement card was given on the last day. Therefore, the students were realizing to wait for the new reinforcement card with a time gap in which one more day was added to the last day they received those cards.

Third Phase: In the third phase, the students received two separate 45-minute orientation sessions in two groups divided on the basis of their age ranges. The first group included first-and second-grade elementary students (7 \& 8 years old) and the second group consisted of third- fourth- and fifth-grade elementary students (ages 9, 10 \& 11). Students were briefed on the listed social skills. The target behaviors were clearly and operationally defined for them. As an example, the "listening skill" was defined as sitting on the chair, looking at the teacher as well as at the blackboard, focusing on what the teacher was saying, avoiding any other activities while listening and taking notes. Two graduate clinical psychology students assisted the researchers in teaching those social skills.

Students were also given instructions how to earn score cards from their teachers. To receive a point card, students had to point at minimum $50 \%$, increasing progressively. The students also learned on how to exchange their point cards with reinforcement cards. They were reminded that higher points were needed for bigger prizes.

Fourth Phase: At the end of each week, students' points were totaled and they were given the option for different prizes according to their obtained total points. The students, however, were urged to forego the smaller prizes for the bigger ones. Therefore, they were reminded that they needed to save their points to earn the bigger prize. Since prizes increased hierarchically in value, the points had to increase cumulatively too. Therefore, students tried to follow the specified target behaviors and to earn their desired prizes. This program was run for one month and points were totaled for each student at the end of the program. Students were awarded different prizes for their total points (including toy cars, balls in different sizes, toy revolver, water paint palette, story books, etc.).

\section{Results}

The findings revealed that students in the experimental group performed socially better than those in the control group. As noted earlier the main research question of this study was, "What is the effect of training self-control procedure on enhancement of the social skills of students with ADHD?” To answer this question, the means of the two groups (experimental and control) were compared at three times (pretest, post-test and follow-up). Since the differences among the means at three times were statistically significant, the null hypothesis was rejected. Table $\mathbf{1}$ shows the descriptive statistics for both groups. 
Table 1.

Mean and SD for social skills of groups measured at three different times.

\begin{tabular}{lllcc}
\hline Test & Group & $\mathrm{N}$ & Mean & $\mathrm{SD}$ \\
\hline \multirow{2}{*}{ Pretest } & Control & 10 & 24.2 & 3.67 \\
& Experimental & 10 & 23.5 & 3.92 \\
\multirow{3}{*}{ Post-test } & Control & 10 & 23.3 & 4.08 \\
& Experimental & 10 & 29.4 & 3.2 \\
\multirow{2}{*}{ Follow-up } & Control & 10 & 23.8 & 4.05 \\
& Experimental & 10 & 29 & 2.98 \\
\hline
\end{tabular}

As Table 1 shows, the means of experimental and control groups did not differ significantly at pretest. However, the means of the experimental groups were significantly different at the post-test and maintained through at the follow-up measurement. A repeated measure of MANOVA was performed to examine the statistical significance of the difference between the means (See Table 2).

As Table 2 shows, the $F$ ratio of 6.86 is statistically significant $\left(\mathrm{F}_{1,19}=6.86, p>.05, \mathrm{DF}=1\right)$ indicating a significant difference between the means of experimental and control groups. In addition, the $F$ ratio for the effect of times produced a significant result of $6.42(p>.01, \mathrm{DF}=2)$. Therefore, there was a significant difference between times of measurement. The time group interaction effect produced a significant $F$ ratio of 10.29 $(p>.001, \mathrm{DF}=2)$. Since the interaction effect was statistically significant, one may conclude that the effect of time on group was different.

A post hoc Tukey HSD test was performed in order to find which means differed significantly from others in the cells produced by the time group interaction effect. Table 3 shows the results of the Tukey HSD analysis. As it can be seen in Table 3, there is a significant difference between experimental group pretest and post-test and follow-up measurement ( $p$ $<.01$ ). Furthermore, there were significant differences between the pretest and post-test in the experimental group, and between the pretest and follow-up measurement in the experimental group $(p<.05)$. Moreover, the means differences between follow-up measurement in the experimental group and the posttest mean in the experimental group and between the post-test and the follow-up measurement in the control group were statistically significant $(p<.05)$. As a result, one may conclude that training self-control techniques had significantly improved the social skills of the participants.

Table 2.

Results of repeated-measures MANOVA examining self-control by ADHD.

\begin{tabular}{lccccc}
\hline Source & $\begin{array}{c}\text { Sum of } \\
\text { squares }\end{array}$ & $\begin{array}{c}\text { Mean } \\
\text { square }\end{array}$ & DF & F & Sig \\
\hline Between-group variance & 678.94 & 214.59 & 19 & & \\
Group & 187.27 & 187.27 & 1 & 6.86 & .017 \\
Error & 491.67 & 27.32 & 18 & & \\
Within-group variance & 459.99 & 117.43 & 40 & & \\
Time & 85.03 & 42.58 & 2 & 6.42 & .004 \\
Time $\times$ Group & 136.43 & 68.22 & 2 & 10.29 & .001 \\
Error & 238.53 & 6.63 & 36 & & \\
Total & 1138.93 & 332.02 & 59 & & \\
\hline
\end{tabular}

Table 3.

Results of Tuckey HSD post-hoc test comparing mean diffrences of group $\times$ time.

\begin{tabular}{llcl}
\hline Group & Comparison group & Mean difference & Sig \\
\hline $\begin{array}{llcl}\text { Experimental } \\
\text { pretest }\end{array}$ & Experimental post-test & -5.9 & .009 \\
& Experimental follow-up & -5.5 & .018 \\
& Control pretest & 5.2 & .029 \\
Experimental & Control post-test & 6.1 & .006 \\
post-test & Control follow-up & 5.6 & .015 \\
& Control pretest & 4.8 & .045 \\
Experimental & Control post-test & 5.7 & .013 \\
follow-up & Control follow-up & 5.2 & .029 \\
\hline
\end{tabular}

\section{Discussion}

As discussed earlier, children with ADHD have difficulties in social functioning in school setting. Hence, in the present study, the social skills of students with ADHD compared with students without ADHD. The subjects in both experimental and control groups were pretested on their social skills. Afterward, the experimental group received self-control training intervention program (as the independent variable) for one month. The social skills test was readminstered as the post-test at the end of the program and as follow-up measurement within one month of the post-test. The results of a repeated measure of MANOVA revealed statistically significant differences between the experimental and control groups. Furthermore, the results of the follow-up measurement indicated that the results were maintained across time. The time group interaction showed that the results of the post-test and the follow-up measurement were not significant for both groups; rather, the post-test scores of the experimental group had significantly changed from the pretest and maintained by the time of the follow-up measurement. The analysis of the results implied that participants' social skills in the experimental group receiving the intervention program had improved.

The findings of this study are consistent with those of Henimrich and colleagues (2004) indicating that teaching self-control techniques would improve the behavior of individuals with ADHD. The results are also in agreement with those of Austin (2003), Murray (2002) and Whittenberg (2004) to the effect that teaching self-control techniques had a significant effect on decreasing problematic behaviors and impulsivity in individuals with ADHD.

Inability to self-control is one of the major problems in children with ADHD. In other words, one may state that children with ADHD are similar to normal ones, except for the fact that typically developing children can control their behaviors in different contexts and occasions. However, individuals suffering from ADHD may be unable to control their behaviors and predict the ensuing consequences. Therefore, teaching self-control techniques to children with ADHD may help them improve their self-control ability and minimize their problems in communication and problematic behaviors and consequently enhance their social skills. The results of the present study support the argument that teaching self-control techniques may be one of the best methods to help students with ADHD improve their behaviors through internal monitoring of their behaviors and 
evaluating the consequences of their behaviors. Since self-control may allow children to manage their behaviors in the absence of watching adults, it may teaches them to take responsibility for their own actions.

Teaching self-control techniques to children may also enable them to provide self-directed feedback on their behaviors. They may learn to evaluate and monitor their behaviors and systematically treat themselves with appropriate rewards for their acceptable behaviors. They may also learn to perform effectively and productively even in the absence of an external agent (e.g. parent, teacher, principal).

Generally speaking, children with ADHD may have problems in their self-control. The results of the present research indicate that teaching self-control techniques may minimize quite a number of the problems of children with ADHD.

Limitations and Suggestions: Like many other studies, the present study was limited in a number of ways. The participants in this study included boys only. Therefore, one must take caution in generalizing the results to the female population. Another limitation is that, the students in the control group might meet and interact with those in the experimental group possibly allowing them to exchange ideas. Additionally, in this study we could not differentiate the participants based on subtypes of ADHD (inattentive, hyperactive-impulsive or combined).

For further research, researchers are encouraged to examine the effect of self-control training on other behavioral-emotional disorders in children and on different age groups. Examining the effect of self-control techniques training on a mild, moderate and severe attention deficit and hyperactivity disorder is also strongly encouraged.

Finally, the researchers encourage teachers and parents to teach self-management and self-control techniques to children with ADHD to explore further implications. As Hughes and Cooper (2008) have mentioned to us in their book: "Changing the child's behavior will take time and medication alone will not provide the child with sufficient support to modify his or her behavior" (p. 90).

\section{REFERENCES}

Abikoff, H. (1991). Cognitive training in ADHD children: Less to it than meets the eye. Journal of Learning Disabilities, 24, 205-209. doi:10.1177/002221949102400404

American Psychiatric Association (2000). Diagnostic and statistical manual of mental disorders (DSM-IV-TR). Washington, DC: Author.

Anastasi, A. \& Urbina, S. (2009). Psychological testing (7th ed.). New York: Prentice Hall.

Austin, H. M. (2003). Use of self-management techniques for the treatment of students diagnosed with ADHD: An empirical investigation of the self-regulation of behavior. Dissertation Abstracts International Section B: The Sciences \& Engineering, 64, 2904.

Barkley, R. A. (1990). A critique of current diagnostic criteria for Attention Deficit-Hyperactivity Disorder: Clinical and research implication. Journal of Developmental and Behavioral Pediatrics, 11, 352-373. doi:10.1097/00004703-199012000-00014

Barkley, R. A. (1997). ADHD and the nature of self-control. New York: Guilford Press.

Braswell, L (1998). Cognitive behavioral approaches as adjunctive treatments for ADHD children and their families. In S. Goldstein, \& M. Goldstein (Eds.), Managing Attention Deficit Hyperactivity Disorder in Children (2nd ed., pp. 533-544), New York: Wiley.

Braswell, L., \& Bloomquist, M. (1991). Cognitive-behavioral Therapy with ADHD children: Child, family and school interventions. New York: Guilford Press.
Cantwell, D. P. (1996).Attention deficit disorder: A review of the past 10 years. Journal of the American Academy of Child and Adolescent Psychiatry, 35, 978-987. doi:10.1097/00004583-199608000-00008

Conners, C. K., \& Jett, J. L. (1999). Attention Deficit Hyperactivity Disorder in adults and children. Kansas City: Compact Clinical.

Dixon, M. R., Hayes, L. J., Binders, L. M., Manthey, S., Sigman, C., \& Zdanowski, D. M. (1998). Using a self-control training procedure to increase appropriate behavior. Journal of Applied Behavior Analysis, 31, 203-210. doi:10.1901/jaba.1998.31-203

Friedman R. J., \& Doyal, G. T. (1992). Management of Children and adolescents with ADHD. New York: Pro-Ed.

Ghanizadeh, A., \& Jafari, P. (2010). Cultural structures of the Persian parents' ratings of ADHD. Journal of Attention Disorders, 13, 369-373. doi:10.1177/1087054709332421

Ghanizadeh, A. (2008). Distribution of symptoms of attention deficithyperactivity disorders in school children of Shiraz, south of Iran, Archives of Iranian Medicine, 1, 618-624.

Gilmore, L., Cuskelly, M., \& Hayes, A. (2003). Self-regulatory behaviors in children with Down syndrome and typically developing children measured using the Goodman Lock Box. Research in Developmental Disabilities, 24, 95-108.

doi:10.1016/S0891-4222(03)00012-X

Goldstein, S. (1995). Understanding and managing children's classroom behavior. New York: Wiley.

Gresham, F. M., \& Elliot, S. N. (1984). Assessment and classification of children's social skills: A review of methods and issues. School Psychology Review, 13, 292-301.

Gresham, F. M., \& Elliott, S. N. (1990). Social skills rating system manual. Circle Pines, MN: American Guidance Service.

Heinrich, H., Gevensleben, H., Freisleder, F. J., Moll, G. H., \& Rothenberger, A. (2004). Training of slow cortical potentials in attention-deficit/hyperactivity disorder: Evidence for positive behavioral and neurophysiological effects. Biological Psychiatry, 55, 772-775. doi:10.1016/j.biopsych.2003.11.013

Hughes, L., \& Cooper, P. (2008). Understanding and supporting children with ADHD: Strategies for teachers, parents and other professionals. London: Sage Publications

Khoushabi, K., \& Pouretemad, H. (2002). Prevalence of attention deficit and hyperactivity disorder in high school students of Tehran. Tehran: University of Rehabilitation and Welfare Press.

Landau, S., Milich, R., \& Diener, M. B. (1998). Peer relations of children with attention-deficit-disordered boys. Journal of Abnormal Child Psychology, 16, 69-81. doi:10.1007/BF00910501

Likert, R. (1932). A technique for measurement of attitudes. Archives of Psychology, 140, 5-55.

Lufi, D., \& Parish-Plass, J. (1995). Personality assessment of children with attention deficit hyperactivity disorder. Journal of Clinical Psychology, 51, 94-99. doi:10.1002/1097-4679(199501)51:1<94::AID-JCLP2270510115>3. $0 . \mathrm{CO} ; 2-\mathrm{W}$

Matson, J. L., \& Ollendick, T. H. (1988). Enhancing children's social skills: Assessment and training. London: Pergamon Press.

Meichenbaum, D. H., \& Goodman, J. (1971). Training impulsive children to talk to themselves. Journal of Abnormal Psychology, 77, 115126. doi: $10.1037 / \mathrm{h} 0030773$

Murray, L. K. (2002). Self-control training in young children. Dissertation Abstracts International Section B: The Sciences \& Engineering, 63, 3017.

Pierangelo, R., \& Giuliani, G. (2008). Classroom management techniques for students with ADHD: A step-by-step guide for educators. Thousand Oaks, CA: Corwin Press.

Shahim, S. (1999). A study of the social skills in educable mentallyretarded children using The Social Skills Rating System. Journal of Psychology and Education, 4, 18-37.

Whittenberg, T. L. (1995). A comparison of the effects of self-control versus social skills training with socially anxious children. Dissertation Abstracts International Section A: Humanities \& Social Sciences, 55, 1889. 